\title{
Medication management support in diabetes: a systematic assessment of diabetes self-management apps
}

\author{
Zhilian Huang ${ }^{1,2^{*}}$ (D), Elaine Lum ${ }^{1,3,4}$, Geronimo Jimenez ${ }^{1}$, Monika Semwal ${ }^{1}$, Peter Sloot ${ }^{5,6,7}$ and Josip Car $^{1}$
}

\begin{abstract}
Background: Smartphone apps are becoming increasingly popular for supporting diabetes self-management. A key aspect of diabetes self-management is appropriate medication-taking. This study aims to systematically assess and characterise the medication management features in diabetes self-management apps and their congruence with best-practice evidence-based criteria.

Methods: The Google Play and Apple app stores were searched in June 2018 using diabetes-related terms in the English language. Apps with both medication and blood glucose management features were downloaded and evaluated against assessment criteria derived from international medication management and diabetes guidelines.

Results: Our search yielded 3369 Android and 1799 iOS potentially relevant apps; of which, 143 apps (81 Android, 62 iOS) met inclusion criteria and were downloaded and assessed. Over half 58.0\% (83/143) of the apps had a medication reminder feature; $16.8 \%$ (24/143) had a feature to review medication adherence; 39.9\% (57/143) allowed entry of medication-taking instructions; 5.6\% (8/143) provided information about medication; and 4.2\% (6/143) displayed motivational messages to encourage medication-taking. Only two apps prompted users on the use of complementary medicine. Issues such as limited medication logging capacity, faulty reminder features, unclear medication adherence assessment, and visually distracting excessive advertising were observed during app assessments.

Conclusions: A large proportion of diabetes self-management apps lacked features for enhancing medication adherence and safety. More emphasis should be given to the design of medication management features in diabetes apps to improve their alignment to evidence-based best practice.
\end{abstract}

Keywords: Health apps, Digital health, Diabetes, Medication adherence, Evidence-based guidance

\section{Background}

Medication adherence, broadly understood as the act of taking medicines as prescribed by the healthcare provider, is important for achieving treatment goals [1]. This is paramount for chronic conditions such as diabetes. However, studies have shown that approximately $33 \%$ of oral medications and $38 \%$ of insulin for type 2 diabetes (T2D) are not taken/used as prescribed [2, 3] due to forgetfulness, inconvenience, negative treatment beliefs,

\footnotetext{
* Correspondence: ZHUANG014@e.ntu.edu.sg

${ }^{1}$ Centre for Population Health Sciences, Lee Kong Chian School of Medicine, Nanyang Technological University, Clinical Sciences Building, Level 18, 11 Mandalay Road, Singapore 308232, Singapore

${ }^{2}$ NTU Institute for Health Technologies (HealthTech NTU), Interdisciplinary Disciplinary School, Nanyang Technological University, Singapore, Singapore Full list of author information is available at the end of the article
}

fear of injections and a myriad of other personal and health system factors [4].

Medication management strategies have been developed and implemented to assist people in adhering to their medications. These strategies include education on disease management, simplification of dosing regimen, counselling, reminders, or a combination of these methods $[5,6]$. Digital solutions have also been studied in the past 20 years to assist in medication adherence. Although research has shown that mobile text messaging can double the odds of medication adherence in chronic diseases [7], more successful interventions often involved the use of two-way communication [8] and were tailored to individual needs $[9,10]$. This suggests the need for innovation

(c) The Author(s). 2019 Open Access This article is distributed under the terms of the Creative Commons Attribution 4.0 International License (http://creativecommons.org/licenses/by/4.0/), which permits unrestricted use, distribution, and 
and a combination of measures that go beyond basic reminders to improve medication adherence.

Smartphone apps have gained popularity in diabetes self-management in recent years. Compared to SMS reminders, smartphone apps have the advantage of performing more sophisticated medication management functions such as pill organisation, tracking of medication-taking, information provision, and adherence assessment [6]. With the rise in the number of smartphone users $[11,12]$ and integration of smartphone apps in daily living [13], a myriad of apps were developed to assist people in adhering to their medications. Despite the large number (approximately 400) of accessible and free apps for medication selfmanagement in the app market in recent years [14], the majority of these apps lacked useful, desirable features for medication adherence [15]. According to national digital health consumer surveys, only $11 \%$ of respondents tracking health goals tracked their medications [16]. Medication adherence is also least likely to be tracked in an app (10\%) amongst other trackable health-related metrics like physical activity, heart rate and sleep [17].

Currently, the large number of available diabetes management apps provides an opportunity to support medication management, but also represents missed opportunities to improve care for people with diabetes with gaps that fall short of users' needs [18]. It is unclear if diabetes apps are adequately incorporating medication management strategies and if app features are aligned with best-practice evidence-based recommendations [19]. Improvements in app quality and utility can only be realised if gaps in app features are identified. We constructed a diagram linking good medication management practice with possible app features and systematically assessed and characterised the medication management features in available apps for T2D self-management. We discussed the implications of our findings in relation to diabetes management and provided suggestions to address the identified gaps.

\section{Methods}

\section{Development of app assessment criteria}

Statements from international medication management guidelines and literature were extracted based on their applicability to chronic disease self-management [20-29]. Similar concepts (i.e. factors) were grouped, mapped with possible app features and assigned a group heading for classification purposes. We then linked the groups of app features by adapting the diagram from Stowasser's medication management pathway [30]. Figure 1 illustrates the relationship between the factors for good medication management practice and possible app features.
The possible app features for diabetes self-management (from Fig. 1) were developed into app assessment criteria (Table 1). Each assessment criterion was mapped back to medication management guidelines. For example, the assessment criteria "The app allows users to assess medication adherence by comparing planned and actual medication taking", operationalised through the app's logging and tracking features, were mapped to guidelines recommending clinicians to "Routinely assess adherence during prescribing, dispensing, and reviewing medicines" for medication adherence. All app assessment criteria had binary responses (Yes/No) for consistency.

\section{App selection and assessment Search strategy}

The app search and selection methods in this study were adapted from principles of a systematic review to ensure minimisation of bias. Diabetes terms were searched to capture apps that were marketed for diabetes selfmanagement. The Google Play and Apple app stores were searched in June 2018 via an app market explorer (https://42matters.com/) which covers both app stores in 55 countries. The search terms used in the English language were "(Diabetes OR Diabetic OR Diabetics) OR (glucose OR glycaemic OR glycemic OR blood sugar OR HbA1c OR A1c) OR insulin", which produced a list of app titles and descriptions for screening.

\section{Screening}

App titles and descriptions were screened for inclusion and exclusion using the following process: a random sample of 100 apps was first screened by two researchers to ensure consistency in the interpretation of the inclusion and exclusion criteria. Differences in interpretation were resolved via consensus discussion. Unclear titles and descriptions were conservatively included for downloading and re-screening until an inter-rater agreement of above $80 \%$ was achieved. Apps available on both the iOS and Android platforms were treated as unique apps due to possible differences in versions across platforms.

The following inclusion and exclusion criteria were used:

Inclusion criteria:

- Apps with medication self-management features

- Apps with any blood glucose logging features

- Apps in the English language

- Free apps and apps requiring payment

Exclusion criteria:

- Patient health portals linking to patients' electronic health records

- Apps that were not updated after January 1, 2017 


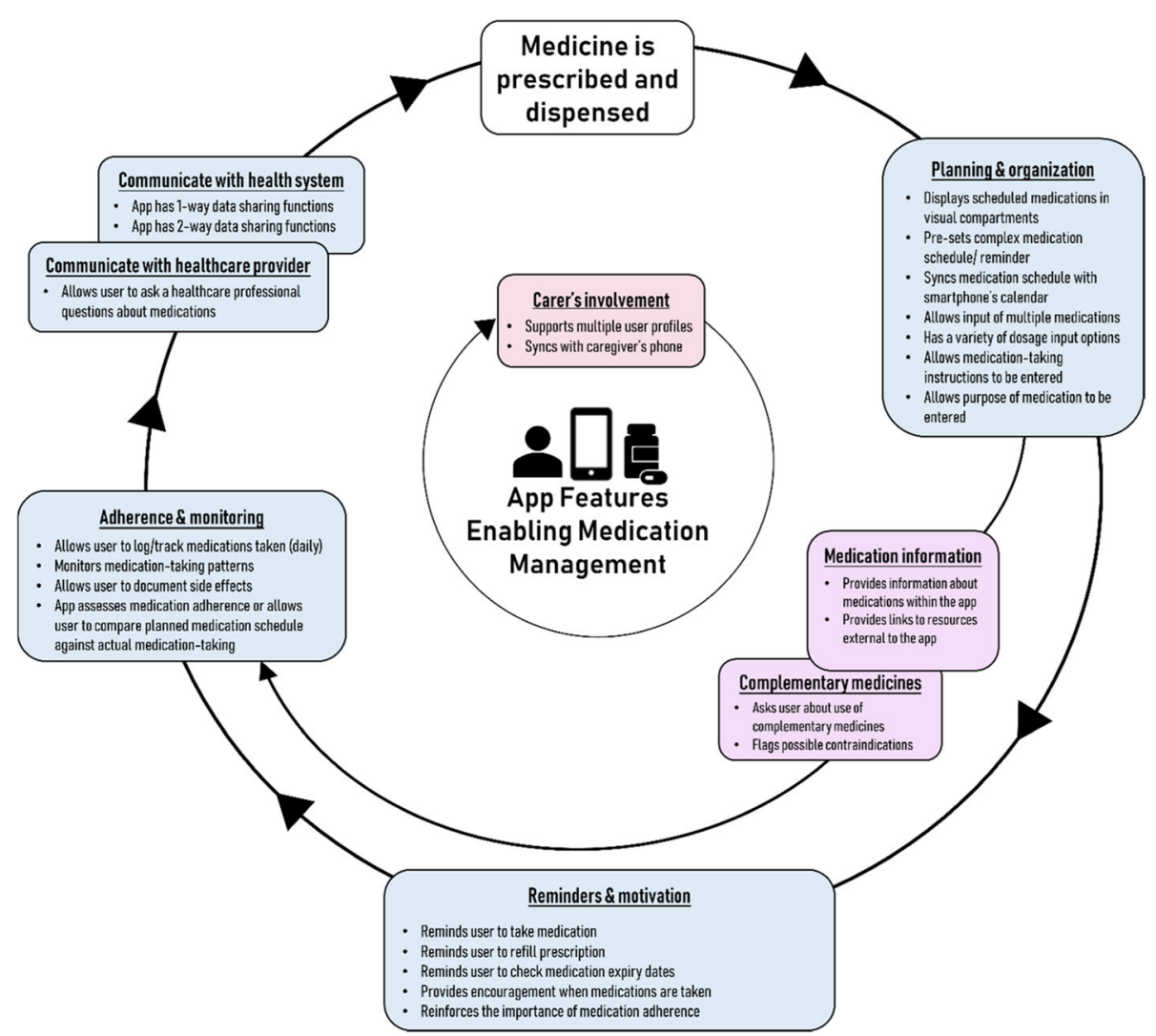

Fig. 1 Diagram of app features mapped with factors for good medication management practice. Statements from international medication management guidelines and literature were grouped according to adaptations from Stowasser's medicines management pathway. App features were then mapped with the groupings to link the features into a medication management pathway. The mapped features were used to develop evidenced-based criteria for app assessment. Different box colours were used to differentiate layers of the medication management app pathway

- Intended for healthcare professionals

- Insulin calculators/bolus correctors only

- Apps with exclusive blood glucose monitoring device tie-in requirement

- Apps duplicated on the same platform

- Apps with regional restrictions

- Technical problems (e.g. crashes, screen hangs, unable to login, unable to download)

\section{App assessments}

The medication management features of selected apps were evaluated against the app assessment criteria. Three apps with extensive features were selected to pilot app assessment and refine the assessment criteria. Team members underwent a calibration exercise to ensure consistency in interpretations. All selected apps were then split among six researchers for assessment (see Additional file 1 for the list of smartphones and their OS system). App developers were contacted for access to restricted apps that were free to download. Apps that could not be accessed within a month of contact were excluded from the study. Free apps which offered additional features upon payment were evaluated with the additional features in place.

\section{Statistical analysis \\ Screening}

Cohen's kappa was used to calculate the inter-rater agreement between two researchers at the screening process. An agreement score of between 0.6 and 0.8 represents a reasonably good agreement between the reviewers [31]; a 0.8 cut-off score was used in this study due to the broad inclusion criteria.

\section{App assessments}

Apps were grouped by platform (i.e. Android, iOS) and profiled according to its features (i.e. reminders, tracking, monitoring) using descriptive statistics. Pearson's chisquared test was used for comparisons between groups. A two-tailed Fisher's exact test was used where the expected 
Table 1 App assessment criteria with the corresponding guidance/evidence extracted from international medication management guidelines and literature

\begin{tabular}{llll}
\hline $\mathrm{S} / \mathrm{N}$ & App assessment criteria & Excerpt of extracted guidance/justification & $\begin{array}{l}\text { References supporting } \\
\text { the guidance }\end{array}$
\end{tabular}

$1 \quad$ Planning and organisation

1.1 The app has a feature that allows the user to display scheduled medications as different visual compartments (e.g. visual pillbox in the app)

1.2 The app has a feature that allows the user to switch between daily and weekly medication schedule displays

1.3 The app has a feature that allows the user to schedule medication-taking on alternate days (e.g. Pill A on Monday, Wednesday, Friday; Pill B on Tuesday, Thursday, Saturday)

The app has a feature to enter the purpose of the medication

1.5 The app has a feature that allows the user to enter special instructions for medication (e.g. taken before food)

The app has a feature that allows the user to organise "take as needed" medications in a separate section from medicines with a fixed regimen

The app has a feature that allows the user to enter/log at least 4 different medications at any given time

The app has a variety of dosage input options (e.g. subcutaneous insulin for diabetes, oral medications)

The app has a feature that allows the user to document allergies (i.e. via prompts/greyed out instructions or a separate tab)

The app has a feature that allows the user to sync medication-taking schedule with the phone calendar

Adherence and monitoring

The app has a feature that allows the user to record the fraction of an actual pill or volume of a liquid medication prescribed (i.e. $1 / 2$ pill or $5 \mathrm{ml}$ of a syrup) to be recorded.

The app has a feature that allows users to document medication-intake

2.3 The app has a feature that allows users to record notes on any medication event (i.e. a "note/comment" section at the logging page or a as a separate tab)

The app has a feature that allows users to document medication side-effects (i.e. via prompts/greyed-out instructions or a separate tab)

The app has a feature that assesses medication adherence by comparing planned and actual medication taking (E.g. the app generates weekly percentage of adherence or has a visual display). Information provision
Reduce dosing complexity: Use blister or compartmentalised boxes to reduce dosing

$[21,24,25,28]$ complexities

Planning and organisation: Develop an individualised, documented self-management plan including the plan's start and review date, conditions being managed, description of the medication (frequency, dose, strength, instructions, known reactions, and allergies, length of treatment)

For user's convenience without having to open a separate calendar to view medication schedule.

Oral tablets may be prescribed as a fraction of one and liquids are prescribed as a specified volume. Apps that do not allow this will be less helpful and could introduce errors.

Monitoring: Record medicines taken, self-monitor the condition and report all adverse reactions.

Adherence assessment: Routinely assess adherence during prescribing, dispensing, 
Table 1 App assessment criteria with the corresponding guidance/evidence extracted from international medication management guidelines and literature (Continued)

\begin{tabular}{|c|c|c|c|}
\hline$\overline{S / N}$ & App assessment criteria & Excerpt of extracted guidance/justification & $\begin{array}{l}\text { References supporting } \\
\text { the guidance }\end{array}$ \\
\hline & $\begin{array}{l}\text { with information about the prescribed } \\
\text { medication }\end{array}$ & \multirow{3}{*}{$\begin{array}{l}\text { understandable, and relevant information } \\
\text { about the medication prescribed. Provide } \\
\text { resources to where information about } \\
\text { medication can be obtained. }\end{array}$} & \\
\hline 3.2 & $\begin{array}{l}\text { The app has a feature that provides users } \\
\text { with resources (in-app or external link) to } \\
\text { access information about the prescribed } \\
\text { medication }\end{array}$ & & \\
\hline 4 & Complementary medicines & & \\
\hline 4.1 & $\begin{array}{l}\text { The app has a feature that asks users about } \\
\text { the use of complementary medicines }\end{array}$ & \multirow{3}{*}{$\begin{array}{l}\text { Complementary medicine: Take into account } \\
\text { all complementary medicines the person is } \\
\text { taking or using, and its purpose. }\end{array}$} & \multirow[t]{3}{*}[20-23,27]{} \\
\hline 4.2 & $\begin{array}{l}\text { The app has a feature that flags possible } \\
\text { contraindications with the use of } \\
\text { complementary medicines }\end{array}$ & & \\
\hline 5 & Reminders & & \\
\hline 5.1 & $\begin{array}{l}\text { The app has a feature that allows users to } \\
\text { set up reminders for taking medications }\end{array}$ & $\begin{array}{l}\text { Reminders: Reminders have shown to improve } \\
\text { adherence to medicines despite inconclusive } \\
\text { evidence. }\end{array}$ & \multirow[t]{2}{*}[20,23,24,28]{} \\
\hline 5.2 & $\begin{array}{l}\text { The app has a feature that allows users to } \\
\text { set up reminders to refill prescriptions }\end{array}$ & $\begin{array}{l}\text { Refill medication: Prescription refill is an } \\
\text { indirect method for measuring medication } \\
\text { adherence, and could alert prescribers and } \\
\text { pharmacists to problems of adherence. }\end{array}$ & \\
\hline 6 & Motivation & & \\
\hline 6.1 & $\begin{array}{l}\text { The app has a feature that provides } \\
\text { statements to motivate users about the } \\
\text { importance of medication adherence }\end{array}$ & \multirow{2}{*}{$\begin{array}{l}\text { Behavioural change: Positive reinforcements } \\
\text { are important in sustaining behavioural change } \\
\text { (Guidelines). Providing consequences and } \\
\text { benefits of effective medication adherence } \\
\text { helps the patient to understand the need and } \\
\text { to establish motivation to adhere to } \\
\text { medication [26]. Positive reinforcements are } \\
\text { important in sustaining behavioural } \\
\text { change [27]. }\end{array}$} & \multirow[t]{2}{*}[21,29]{} \\
\hline 6.2 & $\begin{array}{l}\text { The app has a feature that provides } \\
\text { encouragement when medication is taken } \\
\text { on schedule (i.e. encouraging messages, } \\
\text { "badges or awards") }\end{array}$ & & \\
\hline 7 & Caregiver's involvement & & \\
\hline 7.1 & $\begin{array}{l}\text { The app has a feature that allows users to } \\
\text { sync medication-taking schedule with } \\
\text { caregiver's phone }\end{array}$ & \multirow{3}{*}{$\begin{array}{l}\text { Carer's involvement: Keep an up-to-date list } \\
\text { of all medicines the patient is taking and take } \\
\text { note of any allergic or adverse reactions } \\
\text { to medicines. }\end{array}$} & \multirow[t]{3}{*}[21,24,25,28]{} \\
\hline 7.2 & $\begin{array}{l}\text { The app has a feature that supports multiple } \\
\text { user profiles (e.g. For family members } \\
\text { or carers) }\end{array}$ & & \\
\hline 8 & Communication with healthcare provider & & \\
\hline 8.1 & $\begin{array}{l}\text { The app has a feature that allows users to } \\
\text { contact a healthcare provider regarding } \\
\text { queries on medication }\end{array}$ & \multirow[t]{2}{*}{$\begin{array}{l}\text { Communication with health provider: Establish } \\
\text { the most effective way of communicating } \\
\text { with each patient. }\end{array}$} & \multirow[t]{2}{*}[21,24,25,28,29]{} \\
\hline 9 & Communication with health system & & \\
\hline 9.1 & $\begin{array}{l}\text { The app has a feature that supports data } \\
\text { export }\end{array}$ & $\begin{array}{l}\text { Communication within/across health settings: } \\
\text { Health and social care practitioners should } \\
\text { share relevant information about the person } \\
\text { and their medicines when a person transfers } \\
\text { from one care setting to another. Use the } \\
\text { most effective and secured way with one } \\
\text { or multiple approaches, such as secure } \\
\text { electronic communication. }\end{array}$ & {$[20,21,24,25,28]$} \\
\hline
\end{tabular}

Legend: CG76: Medicines adherence: involving patients in decisions about prescribed medicines and supporting adherence [25]; NG5: Medicines optimisation: the safe and effective use of medicines to enable the best possible outcomes [20]; NCCPC: Clinical guidelines and evidence review for medicines adherence: involving patients in decisions about prescribed medicines and supporting adherence [Full guideline and evidence] [21]; King's fund: Polypharmacy and medicines optimisation: Making it safe and sound [24]; AHRQ [29] (Evidence Report); APAC: Australian Pharmaceutical Advisory Council Guiding principles for medication management in the community [28] 
count is less than five in a group. Statistical significance was set at $p$ value $<0.05$. All analyses were performed using SPSS version 22 [32].

\section{Results}

The search terms yielded 3369 Android and 1799 iOS apps. After title and description screening, 191 (5.7\%) Android and 160 (8.9\%) iOS apps remained for downloading. Apps were further excluded due to their unavailability, exclusive device tie-in requirement, technical issues, not meeting the inclusion criteria (i.e. non-English), and if they were duplicated on the same platform. Restricted apps that received no reply from developers were also excluded from the study. Finally, 143 apps (81 Android, 62 iOS) were downloaded and assessed against the app assessment criteria (Fig. 2).

The search terms "(Diabetes OR Diabetic OR Diabetics) OR (glucose OR glycaemic OR glycemic OR blood sugar OR HbA1c OR A1c) OR insulin" yielded 4876 results from (https://42matters.com). After screening the app descriptions for relevance, 351 apps were downloaded for assessment; of which, 208 apps were excluded due to (i) technical issues, (ii) device tie-in, (iii) not available at app assessment, (iv) regional restriction, (v) do not meet inclusion criteria on second screening, and (vi) duplication of apps on the same platform. Finally, 143 apps (81 Android; 62 iOS) were fully assessed against the app assessment criteria in Table 1.

\section{Characteristics of included apps}

The frequency of app features grouped by platform is shown in Table 2.

\section{Planning and organisation}

More than two thirds of the apps allowed users to input insulin doses $(86.0 \%, 123 / 143)$ and record multiple medications $(68.5 \%, 98 / 143)$, while less than half of the apps allowed users to input special instructions $(39.9 \%, 57 / 143)$ or the purpose $(29.4 \%, 42 / 143)$ of the medication. A low proportion of the apps supported users in managing dosing complexities with digital visual compartments (4.9\%, 7/143), toggling between daily and weekly displays $(2.8 \%, 4 / 143)$, and pre-setting complex medication schedules $(25.9 \%, 37 / 143)$. Few apps also specifically asked the

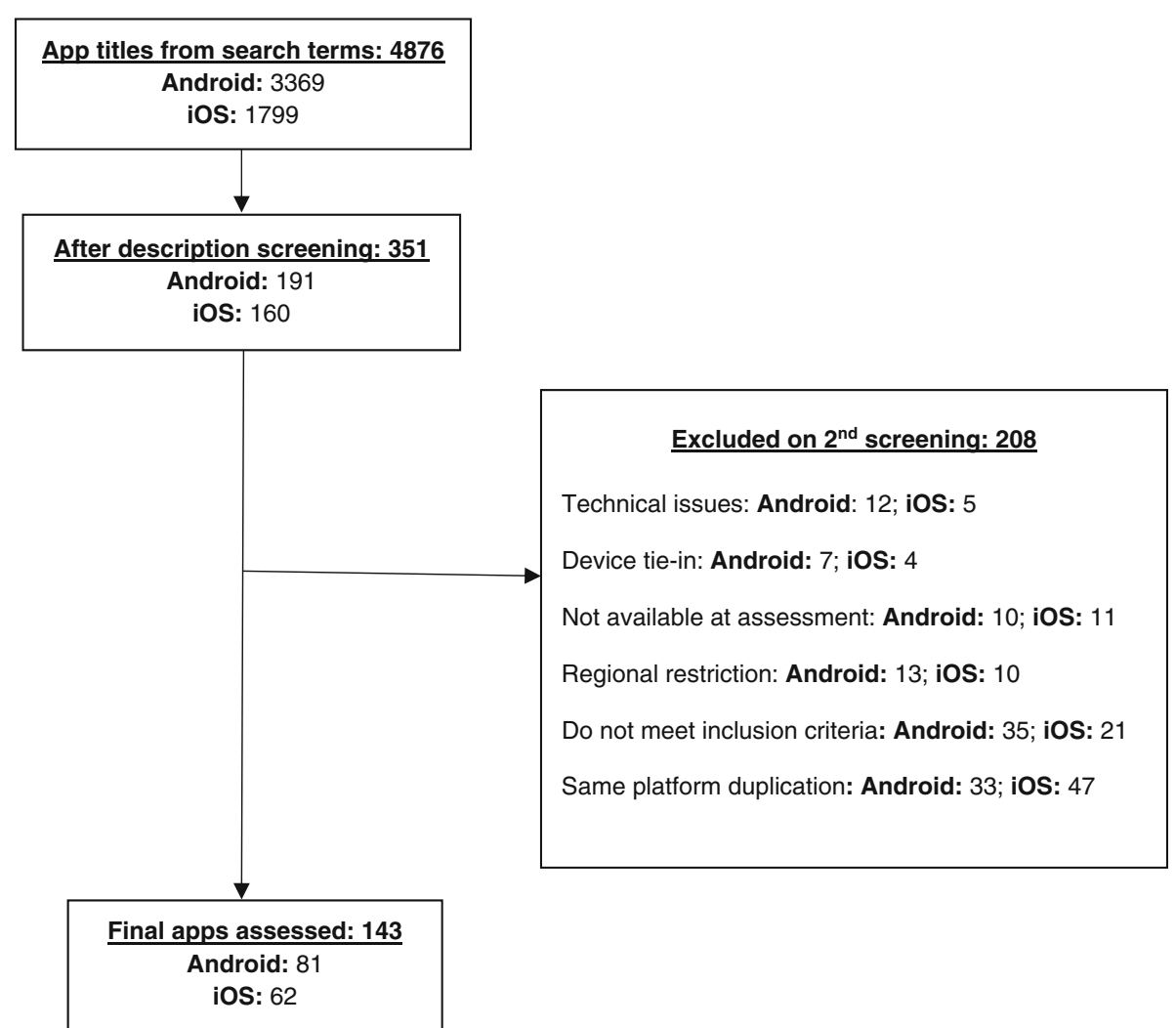

Fig. 2 Flowchart for app selection. The search terms "(Diabetes OR Diabetic OR Diabetics) OR (glucose OR glycaemic OR glycemic OR blood sugar OR HbA1c OR A1c) OR insulin" yielded 4876 results from (https://42matters.com). After screening the app descriptions for relevance, 351 apps were downloaded for assessment; of which, 208 apps were excluded due to (i) technical issues, (ii) device tie-in, (iii) not available at app assessment, (iv) regional restriction, (v) do not meet inclusion criteria on second screening and (vi) duplication of apps on the same platform. Finally, 143 apps (81 Android; 62 iOS) were fully assessed against the app assessment criteria in Table 1 
Table 2 Frequency of app features grouped by platform

\begin{tabular}{|c|c|c|c|c|c|c|}
\hline Classification & & App features & $\begin{array}{l}\text { All apps } \\
(n=143)(\%)\end{array}$ & $\begin{array}{l}\text { Android } \\
(n=81)(\%)\end{array}$ & $\begin{array}{l}\text { iOS } \\
(n=62)(\%)\end{array}$ & $p$ value \\
\hline \multirow[t]{10}{*}{$\begin{array}{l}\text { Planning and } \\
\text { organisation }\end{array}$} & 1.1 & $\begin{array}{l}\text { The app has a feature that allows the user to display } \\
\text { scheduled medications as different visual compartments } \\
\text { (e.g. visual pillbox in the app) }\end{array}$ & $7(4.9)$ & $4(4.9)$ & $3(4.8)$ & $1.000^{\wedge}$ \\
\hline & 1.2 & $\begin{array}{l}\text { The app has a feature that allows the user to switch } \\
\text { between daily and weekly medication schedule } \\
\text { displays }\end{array}$ & $4(2.8)$ & $3(3.7)$ & $1(1.6)$ & $0.633^{\wedge}$ \\
\hline & 1.3 & $\begin{array}{l}\text { The app has a feature that allows the user to schedule } \\
\text { medication-taking on alternate days (e.g. Pill A on } \\
\text { Monday, Wednesday, Friday; Pill B on Tuesday, } \\
\text { Thursday, Saturday) }\end{array}$ & $37(25.9)$ & $24(29.6)$ & $13(21.0)$ & 0.241 \\
\hline & 1.4 & $\begin{array}{l}\text { The app has a feature to enter the purpose of the } \\
\text { medication }\end{array}$ & $42(29.4)$ & $22(27.2)$ & $20(32.3)$ & 0.507 \\
\hline & 1.5 & $\begin{array}{l}\text { The app has a feature that allows the user to enter } \\
\text { special instructions for medication (e.g. taken } \\
\text { before food) }\end{array}$ & $57(39.9)$ & $33(40.7)$ & $24(38.7)$ & 0.806 \\
\hline & 1.6 & $\begin{array}{l}\text { The app has a feature that allows the user to organise } \\
\text { "take as needed" medications in a separate section } \\
\text { from medicines with a fixed regimen }\end{array}$ & $12(8.4)$ & $6(7.4)$ & $6(9.7)$ & 0.628 \\
\hline & 1.7 & $\begin{array}{l}\text { The app has a feature that allows the user to enter/log } \\
\text { at least } 4 \text { different medications at any given time }\end{array}$ & $98(68.5)$ & $56(69.1)$ & $42(67.7)$ & 0.859 \\
\hline & 1.8 & $\begin{array}{l}\text { The app has a variety of dosage input options } \\
\text { (e.g. subcutaneous insulin for diabetes, oral medications) }\end{array}$ & $123(86.0)$ & $66(81.5)$ & $57(91.9)$ & 0.074 \\
\hline & 1.9 & $\begin{array}{l}\text { The app has a feature that allows the user to document } \\
\text { allergies (i.e. via prompts/greyed out instructions or } \\
\text { a separate tab) }\end{array}$ & $5(3.5)$ & $4(4.9)$ & $1(1.6)$ & $0.389 \wedge$ \\
\hline & 1.10 & $\begin{array}{l}\text { The app has a feature that allows the user to sync } \\
\text { medication-taking schedule with the phone calendar }\end{array}$ & $7(4.9)$ & $2(2.5)$ & $5(8.1)$ & $0.239 \wedge$ \\
\hline \multirow[t]{5}{*}{$\begin{array}{l}\text { Monitoring and } \\
\text { adherence }\end{array}$} & 2.1 & $\begin{array}{l}\text { The app has a feature that allows the user to record } \\
\text { the fraction of an actual pill or volume of a liquid } \\
\text { medication prescribed (i.e. } 1 / 2 \text { pill or } 5 \mathrm{ml} \text { of syrup) } \\
\text { to be recorded. }\end{array}$ & $83(58.0)$ & 45 (55.6) & $38(61.3)$ & 0.491 \\
\hline & 2.2 & $\begin{array}{l}\text { The app has a feature that allows users to document } \\
\text { medication-intake }\end{array}$ & $112(78.3)$ & $57(70.4)$ & $55(88.7)$ & $0.008^{*}$ \\
\hline & 2.3 & $\begin{array}{l}\text { The app has a feature that allows users to record } \\
\text { notes on any medication event (i.e. a "note/comment" } \\
\text { section at the logging page or as a separate tab) }\end{array}$ & $70(49.0)$ & $35(43.2)$ & $35(56.5)$ & 0.116 \\
\hline & 2.4 & $\begin{array}{l}\text { The app has a feature that allows users to document } \\
\text { medication side-effects (i.e. via prompts/greyed-out } \\
\text { instructions or a separate tab) }\end{array}$ & $5(3.5)$ & $4(4.9)$ & $1(1.6)$ & $0.389 \wedge$ \\
\hline & 2.5 & $\begin{array}{l}\text { The app has a feature that assesses medication } \\
\text { adherence by comparing planned and actual } \\
\text { medication taking (e.g. the app generates weekly } \\
\text { percentage of adherence or has a visual display). }\end{array}$ & $24(16.8)$ & $17(21.0)$ & $7(11.3)$ & 0.175 \\
\hline \multirow[t]{2}{*}{ Information provision } & 3.1 & $\begin{array}{l}\text { The app has a feature that provides users with } \\
\text { information about the prescribed medication }\end{array}$ & $12(8.4)$ & $6(7.4)$ & $6(9.7)$ & 0.628 \\
\hline & 3.2 & $\begin{array}{l}\text { The app has a feature that provides users with } \\
\text { resources (in-app or external link) to access information } \\
\text { about the prescribed medication }\end{array}$ & $8(5.6)$ & $4(4.9)$ & $4(6.5)$ & $0.727 \wedge$ \\
\hline \multirow[t]{2}{*}{$\begin{array}{l}\text { Complementary } \\
\text { medicines }\end{array}$} & 4.1 & $\begin{array}{l}\text { The app has a feature that asks users about the use } \\
\text { of complementary medicines }\end{array}$ & $2(1.4)$ & $0(0.0)$ & $2(3.2)$ & $0.186 \wedge$ \\
\hline & 4.2 & $\begin{array}{l}\text { The app has a feature that flags possible } \\
\text { contraindications with the use of complementary } \\
\text { medicines }\end{array}$ & $0(0.0)$ & $0(0.0)$ & $0(0.0)$ & $1.000 \wedge$ \\
\hline \multirow[t]{2}{*}{ Reminders } & 5.1 & $\begin{array}{l}\text { The app has a feature that allows users to set up } \\
\text { reminders for taking medications }\end{array}$ & $83(58.0)$ & $47(58.0)$ & $36(58.1)$ & 0.996 \\
\hline & 5.2 & The app has a feature that allows users to set up & $9(11.1)$ & $6(9.7)$ & $15(10.5)$ & 0.782 \\
\hline
\end{tabular}


Table 2 Frequency of app features grouped by platform (Continued)

\begin{tabular}{|c|c|c|c|c|c|c|}
\hline Classification & & App features & $\begin{array}{l}\text { All apps } \\
(n=143)(\%)\end{array}$ & $\begin{array}{l}\text { Android } \\
(n=81)(\%)\end{array}$ & $\begin{array}{l}\mathrm{iOS} \\
(n=62)(\%)\end{array}$ & $p$ value \\
\hline & & reminders to refill prescriptions & & & & \\
\hline \multirow[t]{2}{*}{ Motivation } & 6.1 & $\begin{array}{l}\text { The app has a feature that provides statements to } \\
\text { motivate users about the importance of medication } \\
\text { adherence }\end{array}$ & $8(5.6)$ & $3(3.7)$ & $5(8.1)$ & $0.293 \wedge$ \\
\hline & 6.2 & $\begin{array}{l}\text { The app has a feature that provides encouragement } \\
\text { when medication is taken on schedule (i.e. encouraging } \\
\text { messages, "badges or awards") }\end{array}$ & $6(4.2)$ & $3(3.7)$ & $3(4.8)$ & $1.000^{\wedge}$ \\
\hline \multirow[t]{2}{*}{ Caregiver's involvement } & 7.1 & $\begin{array}{l}\text { The app has a feature that allows users to sync } \\
\text { medication-taking schedule with caregiver's phone }\end{array}$ & $9(6.3)$ & $5(6.2)$ & $4(6.5)$ & $1.000^{\wedge}$ \\
\hline & 7.2 & $\begin{array}{l}\text { The app has a feature that supports multiple user } \\
\text { profiles (e.g. For family members or carers) }\end{array}$ & $22(15.4)$ & $11(13.6)$ & $11(17.7)$ & 0.494 \\
\hline $\begin{array}{l}\text { Communication with } \\
\text { healthcare provider }\end{array}$ & 8.1 & $\begin{array}{l}\text { The app has a feature that allows users to contact } \\
\text { a healthcare provider regarding queries on } \\
\text { medication }\end{array}$ & $16(11.2)$ & 7 (8.6) & $9(14.5)$ & 0.269 \\
\hline $\begin{array}{l}\text { Communication } \\
\text { with health system }\end{array}$ & 9.1 & $\begin{array}{l}\text { The app has a feature that supports } \\
\text { data export }\end{array}$ & $89(62.7)$ & $44(55.0)$ & $45(72.6)$ & $0.036^{*}$ \\
\hline
\end{tabular}

$\wedge$ Two-tailed $p$ value calculated using Fisher's exact test as the expected count is less than 5 in at least a group

* Statistical significance $p<0.05$ in the comparison between Android and iOS app features

user to document allergies $(3.5 \%, 5 / 143)$ or allowed the user to sync medication schedules with the smartphone's calendar $(4.9 \%, 7 / 143)$. No differences in app features were observed between the operating platforms.

\section{Monitoring and adherence}

A significantly higher proportion of iOS apps had a basic medication tracking feature (Android 70.4\%, 57/81; iOS 88.7\%, 55/62; $p=0.008$ ) compared with Android apps. Although the note-taking feature of the apps $(49.0 \%$, $70 / 143$ ) allowed free text entry, very few specifically asked the user to document medication side-effects $(3.5 \%, 5 / 143)$. More than half of the apps allowed recording of dose fractions (58\%, 83/143), but 16.8\% (24/143) allowed the user to review medication adherence by comparing planned and actual medication taking.

\section{Medication information}

Few apps provided in-app medication information $(8.4 \%$, $12 / 143$ ) or external resources to medication information (5.6, 8/143\%). Two iOS apps prompted the user on the use of complementary medicine, but none of these apps were able to flag possible contraindications with the use of complementary medicines.

\section{Reminders, motivation and caregiver's involvement} Just over half of the apps $(58.0 \%, 83 / 143)$ had a medication reminder feature. Few apps were able to remind the user to refill their medication $(11.1 \%, 9 / 143)$, reinforced the importance of medication adherence $(5.6 \%, 8 / 143)$ or encouraged medication-taking as scheduled with motivational messages $(4.2 \%, 6 / 143)$. There were also very few apps that supported caregiver's involvement, such as supporting multiple user profiles $(15.4 \%, 22 / 143)$ or enabling data syncing with a caregiver's phone $(6.3 \%, 9 / 143)$.

\section{Communication with provider and health system}

Few apps allowed the user to ask a health professional questions about medications $(11.2 \%, 16 / 143)$. For one-way data sharing, a significantly higher proportion of iOS apps had data export features (Android 55.0\%, 44/81; iOS $72.6 \%, 45 / 62 ; p=0.036)$.

\section{Additional findings}

We further compared Android apps with < 100,000 downloads against those with higher downloads $(\geq 100,000)$ (Additional file 2). Although only a small number (17/81) of apps were downloaded $\geq 100,000$ times, a significantly higher proportion of these apps have features that allowed the user to separate medications into "take as needed" sections, document medication-intake, vary dosage input options, set up reminders to refill prescriptions, sync medication-taking schedule with caregiver's phone, support multiple user profiles and support data export. We were unable to analyse iOS apps in the same manner as the number of downloads was not available from the Apple app store.

Several additional issues were found during the app assessments. First, the medication logging feature of some apps was limited by the absence of features such as timestamp, dosage, measurement unit and medication label. For example, one app restricted oral medications input to a maximum dosage of $99.9 \mathrm{mg}$ despite the much higher dosage of some diabetes oral medications. Another app limited medication label to "medication 1" and "medication 2". A few other apps did not allow 
medication logging to be retrospective nor allowed the user to tag an event (i.e. physical activity or a meal) to the medication. Second, some apps had reminder features which did not allow the user to set a recurring alarm nor pre-set a medication-taking schedule. In addition, a few apps had hard-to-find reminder features, faulty alarms that did not work or could not be stopped and delayed notifications. Lastly, we observed one app with inaccurate adherence tracking. The app divided the percentage of medication "taken" and "skipped" in a pie chart without differentiating the type of medication nor the time period of the entry. Other issues include visually distracting advertisements (subjective to assessor's judgement), inability to set up a personal account, poor user interface and functional errors during usage (i.e. crashes).

\section{Discussion}

We identified, downloaded and systematically evaluated 143 apps against assessment criteria derived from international medication management guidelines. There were few differences in app features between Android and iOS apps except for a higher proportion of iOS apps having medication-intake documentation and data export features. Most of the assessed apps, including apps with higher downloads $(\geq 100,000)$, have basic logging and tracking features for diabetes medication, but lacked features that could enhance medication adherence and safety. We identified the following gaps in the assessed apps. First, many diabetes apps lacked any form of medication management features, which concurs with a 2017 study which found that only $50 \%$ of the highest rated iOS diabetes management apps had medication adherence features [33]. A separate study by our team which employed a similar search strategy also found that only $43 \%$ of the accessible diabetes selfmanagement apps had medication management features [34]. This may be attributed to a lack of emphasis given to medication adherence in diabetes management. Amongst the assessed apps with medication management features, a large proportion did not have important features such as a basic reminder feature, the capability to enter medication-taking instructions and medication adherence review. Apps devoid of essential features for enhancing medication adherence are less likely to be useful in helping users adhere to their medications.

Second, less than $10 \%$ of the apps provided any information on diabetes medication or allowed the user to communicate with a healthcare professional. Although this feature is more important for users needing to adjust to a new medication therapy, having information on medication will be beneficial as diabetes is likely to progress over time. Third, only two iOS apps prompted the user if complementary medicine was being used. The use of complementary medicine is common in many cultures and can lead to contraindications [35]. Stopping conventional medication in favour of complementary medicine can also lead to ineffective or adverse treatment outcomes. It would be important for app developers to include a cautionary message or features to alert users to potential contraindications. Documentation of allergies is also important to flag possible medication or food-related contraindication but only $3.5 \%$ of the assessed apps have this capability.

Fourth, less than $5 \%$ of the apps had features that provided any form of motivation to the user. A few apps that encouraged medication adherence had interactive features that could possibly increase the time spent on the app. Sustained app use may increase medicationtaking awareness of users who may otherwise not remember to take their medications. Lastly, about $40 \%$ of the apps do not allow data export, which can assist the individual or a healthcare provider to review treatment plans and goals.

An explanation for the lack of evidence-based features in health apps may be in the absence of healthcare providers' involvement in the development of the app [19]. Only $13.6 \%$ of the apps for medication adherence were developed with the involvement of a healthcare provider and only $1 \%$ of the apps were evidence-based according to another study [14]. Intermittent app use or app intervention failure may sometimes be caused by a lack of useful app features rather than apps being ineffective per se. Many medication adherence app intervention studies focused on reminding the user to take their medications, but the quality of reminder features and alignment with evidence-based recommendations were unclear [36, 37]. Assessing the app against a medication management checklist (as illustrated in Fig. 1) before the intervention will better align the app for its purpose.

While our study focused on users with T2D, $86 \%$ of the assessed apps allow users to log and track insulin doses and hence can also be used by people with type 1 diabetes (T1D). However, adherence to insulin is more challenging than to oral medications due to barriers such as fear of injections, embarrassment of injecting in public, concerns over cost and side effects such as hypoglycaemia) [3, 38, 39]. These barriers cannot be overcome solely by the use of a medication management app, although apps could potentially support adherence to insulin therapy via incorporating patient education.

Strengths of this study include that our app assessment criteria were developed referring to evidence-based guidelines and covered a broader scope on medication management compared to other studies $[6,15]$. We also assessed free apps and apps requiring payment which were not limited to one country's app store. 
Despite attempts to minimise bias, there were limitations to the study. We were unable to cover the entire spectrum of medication management apps. Instead, we chose to focus on diabetes due to its prevalence and the need for long-term medication management. The assessment may also not reflect the current state of the apps due to constant updates. However, we attempted to cover all apps at a particular time point and believe that our findings remain unchanged as a previous study showed that the quality of apps in terms of alignment with evidence-based guidelines did not improve within a 2 -year period [40]. The app assessment criteria for this study were selected based on their perceived usefulness to people with T2D requiring long-term medication management. Other criteria such as focusing on shared decision-making when medications are not taken as intended could be derived for future assessments. Additionally, we did not investigate the app's ability to flag medication contraindications nor assessed the content of the medication information provided in these apps. Although the app assessment criteria were developed from the perspective of chronic disease management, we believe we covered the app features important for medication management in diabetes. Since diabetes self-management requires additional self-care activities such as blood glucose monitoring, physical activity and diet modifications, other features of the app should be considered in assessing the overall quality of the app.

A minimum standard (i.e. certification or selection of apps using an evidence-based checklist) could be one way to raise the standard of medication management features of apps. The implementation of the NHS digital library and the FDA "precertification" programme for mobile apps are precedents of tools to objectively evaluate apps, although gaps still exist in the app marketplace in meeting patients' and clinicians' needs [41]. We also believe that app stores should play a greater role in quality assurance of health/medical apps. In addition to certification, health app developers should take active steps to ensure that their apps meet minimum standards by co-designing apps with potential users and by continuing to upgrade their app. Healthcare providers can take a more active role in participating in app co-design and work with their patients to effectively use an app to manage chronic conditions. Researchers planning for medication adherence app intervention studies should also be aware of the shortcomings of current apps when evaluating the effectiveness of these apps in improving medication adherence.

The list of assessment criteria is non-exhaustive and should be tailored to patient needs and advancements in technology. Given that these assessment criteria may be applicable to medication management of other chronic diseases, future studies can explore apps specific to other chronic diseases to determine if similar gaps exist. Studies can also explore the usability of these apps for better patient experience, and the efficacy of the medication management features in improving medication adherence in different settings.

\section{Conclusions}

Our systematic, broad and evidence-based assessment of smartphone apps provides an overview of medication management features of diabetes self-management apps. A large proportion of the apps lacked features that were useful for enhancing medication adherence and safety, such as the capability to enter allergies and medicationtaking instructions, functional reminders, information provision and prompts for the usage of complementary medicine. These gaps represent missed opportunities for better app features which can potentially enhance digital medication management in people with T2D. More emphasis should be given to the inclusion and design of medication management features in diabetes apps. Healthcare providers, app developers and researchers should be involved in the co-design of health apps in order to improve their quality and be aware of the shortcomings of current apps when making recommendations about their effectiveness.

\section{Additional files}

Additional file 1: List of smartphones and their operating systems used for app assessment. (DOCX $15 \mathrm{~kb}$ )

Additional file 2: Frequency of app features grouped by number of downloads (Android apps only). (DOCX 26 kb)

Abbreviations

T1D: Type 1 diabetes; T2D: Type 2 diabetes

\section{Acknowledgements}

We wish to acknowledge Dr. Ming Keat Sng (MKS), Dr. Li (LL) and Ms. My Linh Thai (MLT) for their input in piloting and refining the app assessment criteria; and Ms. Christina Tan (CT) and Ms. My Linh Thai (MLT) for their assistance in app assessment. HZL would like to acknowledge funding from the NTU Research Scholarship.

\section{Authors' contributions}

$\mathrm{ZH}$ conceptualised and contributed to the development and refinement of the medication management diagram, app assessment criteria, screened apps, assessed apps, cleaned and analysed data, interpreted data, drafted and revised the manuscript. EL co-conceptualised the medication management diagram, provided critical input into developed app assessment criteria and methods, contributed to refining app assessment criteria, assessed apps, interpreted data and revised the manuscript. GJ contributed to refining the app assessment criteria, assessed apps, contacted app developers for restricted apps in order to gain access, interpreted data, revised the manuscript. MS contributed to the development of app assessment criteria, assessed apps and reviewed the draft manuscript. PS provided critical input into the study and critical review of the draft manuscript. JC conceptualised the study, obtained the funding, supervised the team and provided critical input into all stages of the study, and critical review of the draft manuscript. All authors read and approved the final manuscript. 


\section{Funding}

This study was funded by Nanyang Technological University, Singapore, through (a) the Centre for Population Health Sciences (CePHaS), Lee Kong Chian School of Medicine, Nanyang Technological University, Singapore; (b) the Ageing Research Institute for Society and Education (ARISE), Nanyang Technological University, Singapore; and (c) the Institute for Health Technologies (HealthTech NTU), Nanyang Technological University, Singapore. The funder did not have direct involvement in the research including manuscript preparation, apart from employing the authors. The research presented in this article is solely the responsibility of the authors and does not reflect the views of the funder.

\section{Availability of data and materials}

The datasets used and/or analysed during the current study are available from the corresponding author on reasonable request.

\section{Ethics approval and consent to participate}

Not applicable

\section{Consent for publication}

All authors reviewed and approved the final version of the manuscript prior to submission.

\section{Competing interests}

The authors declare that they have no competing interests.

\section{Author details \\ ${ }^{1}$ Centre for Population Health Sciences, Lee Kong Chian School of Medicine, Nanyang Technological University, Clinical Sciences Building, Level 18, 11 Mandalay Road, Singapore 308232, Singapore. ${ }^{2}$ NTU Institute for Health Technologies (HealthTech NTU), Interdisciplinary Disciplinary School, Nanyang Technological University, Singapore, Singapore. ${ }^{3}$ Institute of Health and Biomedical Innovation, Queensland University of Technology, Brisbane, Australia. ${ }^{4}$ School of Clinical Sciences, Faculty of Health, Queensland University of Technology, Brisbane, Australia. ${ }^{5}$ Institute for Advanced Study, University of Amsterdam, Amsterdam, The Netherlands. 'TTMO University, Saint Petersburg, Russia. ${ }^{7}$ Complexity Institute, Nanyang Technological University, Singapore, Singapore.}

Received: 26 March 2019 Accepted: 10 June 2019

Published online: 17 July 2019

\section{References}

1. Osterberg L, Blaschke T. Adherence to medication. N Engl J Med. 2005; 353(5):487-97.

2. Cramer JA. A systematic review of adherence with medications for diabetes Diabetes Care. 2004;27(5):1218-24.

3. Krass I, Schieback P, Dhippayom T. Adherence to diabetes medication: a systematic review. Diabet Med. 2015;32(6):725-37.

4. Jin J, Sklar GE, Oh VMS, Li SC. Factors affecting therapeutic compliance: a review from the patient's perspective. Ther Clin Risk Manag. 2008;4(1):269.

5. Nieuwlaat R, Wilczynski N, Navarro T, Hobson N, Jeffery R, Keepanasseril A, et al. Interventions for enhancing medication adherence. Cochrane Database Syst Rev. 2014(11).

6. Dayer L, Heldenbrand S, Anderson P, Gubbins PO, Martin BC. Smartphone medication adherence apps: potential benefits to patients and providers. $J$ Am Pharm Assoc. 2013;53(2):172-81.

7. Thakkar J, Kurup R, Laba T-L, Santo K, Thiagalingam A, Rodgers A, et al. Mobile telephone text messaging for medication adherence in chronic disease: a meta-analysis. JAMA Intern Med. 2016;176(3):340-9.

8. Park LG, Howie-Esquivel J, Dracup K. A quantitative systematic review of the efficacy of mobile phone interventions to improve medication adherence. J Adv Nurs. 2014;70(9):1932-53.

9. Pop-Eleches C, Thirumurthy H, Habyarimana JP, Zivin JG, Goldstein MP, De Walque D, Mackeen L, Haberer J, Kimaiyo S, Sidle J. Mobile phone technologies improve adherence to antiretroviral treatment in a resourcelimited setting: a randomized controlled trial of text message reminders. AIDS (London, England). 2011;25(6):825.

10. Vervloet M, van Dijk L, Santen-Reestman J, van Vlijmen B, van Wingerden $P$, Bouvy ML, et al. SMS reminders improve adherence to oral medication in type 2 diabetes patients who are real time electronically monitored. Int J Med Inform. 2012;81(9):594-604.

11. The growing value of digital health: evidence and impact on human health and the healthcare system. IQVIA institute for Human Data Science; 2017. Available from: https://www.iqvia.com/institute/reports/the-growing-valueof-digital-health. [cited 2019 March 12]

12. Atiken M, Lyle J. Patient adoption of mHealth: use, evidence and remaining barriers to mainstream acceptance: IMS Institute For Healthcare Informatics; 2015. Available from: https://www.iqvia.com/-/media/iqvia/pdfs/institutereports/patient-adoption-of-mhealth.pdf. [cited 2019 March 12]

13. Car J, Tan WS, Huang Z, Sloot P, Franklin BD. eHealth in the future of medications management: personalisation, monitoring and adherence. BMC Med. 2017;15(1):73.

14. Ahmed I, Ahmad NS, Ali S, Ali S, George A, Danish HS, Uppal E, Soo J, Mobasheri MH, King D. Medication adherence apps: review and content analysis. JMIR mHealth UHealth. 2018;6(3):e62.

15. Santo K, Richtering SS, Chalmers J, Thiagalingam A, Chow CK, Redfern J. Mobile phone apps to improve medication adherence: a systematic stepwise process to identify high-quality apps. JMIR mHealth UHealth. 2016;4(4):e132.

16. Zweig M, Shen J, Jug L: Healthcare consumers in a digital transition. Rock Health. 2017. Available from: https://rockhealth.com/reports/healthcareconsumers-in-a-digital-transition/. [cited 2019 March 12]

17. Adams A, Shankar M, Tacco H: 50 things we now know about digital health consumers. Rock Health; 2016. Available from: https://rockhealth.com/ reports/digital-health-consumer-adoption-2016/. [cited 2019 March 12]

18. Lum E, Jimenez G, Huang Z, Thai L, Semwal M, Boehm BO, Car J. Decision support and alerts of apps for self-management of blood glucose for type 2 diabetes app-based decision support and alerts for blood glucose selfmanagement in type 2 DiabetesLetters. JAMA. 2019;321(15):1530-2.

19. Jimenez G, Lum E, Car J. Examining diabetes management apps recommended from a Google search: content analysis. JMIR mHealth UHealth. 2019;7(1):e11848.

20. National Institute for Health and Care Excellence N: Medicines Optimisation: The Safe and Effective Use of Medicines to Enable the Best Possible Outcomes. In. http://nice.org.uk/guidance/ng5. National Institute for Health and Care Excellence; 2015. Accessed 25 Jan 2019.

21. Nunes V, Neilson J, O'flynn N, Calvert N, Kuntze S, Smithson H, Benson J, Blair J, Bowser A, Clyne W. Clinical guidelines and evidence review for medicines adherence: involving patients in decisions about prescribed medicines and supporting adherence. London: National Collaborating Centre for Primary Care and Royal College of General Practitioners; 2009. p. 364.

22. Usherwood T. Encouraging adherence to long-term medication. Aust Prescr. 2017:40(4):147.

23. Viswanathan $\mathrm{M}$, Golin CE, Jones CD, et al. Interventions to improve adherence to self-administered medications for chronic diseases in the United States: a systematic review. Ann Intern Med. 2012;157(11):785-95.

24. Duerden M, Avery T, Payne R: Polypharmacy and medicines optimisation. Making it safe and sound London: the King's fund 2013.

25. National Institute for Health and Care Excellence N: Medicines adherence: involving patients in decisions about prescribed medicines and supporting adherence. In. https://www.nice.org.uk/guidance/cg76. National Institute for Health and Care Excellence; 2009. Accessed 25 Jan 2019.

26. Ruppar TM, Dobbels F, Lewek P, Matyjaszczyk M, Siebens K, De Geest SM. Systematic review of clinical practice guidelines for the improvement of medication adherence. Int J Behav Med. 2015;22(6):699-708.

27. Bosworth HB, Zullig LL, Mendys P, Ho M, Trygstad T, Granger C, Oakes MM, Granger BB. Health information technology: meaningful use and next steps to improving electronic facilitation of medication adherence. JMIR Med Inform. 2016:4(1):e9.

28. Australian Pharmaceutical Advisory Council. Guiding principles for medication management in the community. Canberra: Commonwealth of Australia; 2006.

29. Viswanathan M, Golin CE, Jones CD, Ashok M, Blalock S, Wines RC, CokerSchwimmer EJ, Grodensky CA, Rosen DL, Yuen A. Closing the quality gap: revisiting the state of the science (vol. 4: medication adherence interventions: comparative effectiveness); 2012.

30. Stowasser DA, Allinson YM, O'Leary M. Understanding the medicines management pathway. J Pharm Pract Res. 2004;34(4):293-6.

31. McHugh ML. Interrater reliability: the kappa statistic. Biochemia Med. 2012 22(3):276-82.

32. Corp I. IBM SPSS statistics for windows, version 22.0. Armonk: IBM Corp; 2013.

33. Martinez M, Park SB, Maison I, Mody V, Soh LS, Parihar HS. iOS Appstorebased phone apps for diabetes management: potential for use in medication adherence. JMIR Diabetes. 2017;2(2):e12. 
34. Soljak M, Lum E, Huang Z, Jiminez G, Li L, Sng MK, Semwal M, Thai ML, Bajpai S, Zhang J, et al. Developing a global assessment framework for health apps targeted at elderly users with type 2 diabetes mellitus. In: 2nd ARISE RESEARCH SYMPOSIUM Healthy \& Active community and Ageing Workforce: Ageing Research Institute for Society and Education, Nanyang Technological Univerisity; 2018.

35. Covington MB. Traditional Chinese medicine in the treatment of diabetes. Diabetes Spectrum. 2001;14(3):154.

36. Becker S, Kribben A, Meister S, Diamantidis CJ, Unger N, Mitchell A. User profiles of a smartphone application to support drug adherence-experiences from the iNephro project. PLoS One. 2013:8(10):e78547.

37. Mira JJ, Navarro I, Botella F, Borrás F, Nuño-Solinís R, Orozco D, IglesiasAlonso F, Pérez-Pérez P, Lorenzo S, Toro N. A Spanish pillbox app for elderly patients taking multiple medications: randomized controlled trial. J Med Internet Res. 2014;16(4):e99.

38. Sarbacker GB, Urteaga EM. Adherence to insulin therapy. Diabetes Spectrum. 2016;29(3):166

39. Davies M, Gagliardino JJ, Gray L, Khunti K, Mohan V, Hughes R. Realworld factors affecting adherence to insulin therapy in patients with type 1 or type 2 diabetes mellitus: a systematic review. Diabetic Med. 2013;30(5):512-24.

40. Huckvale K, Morrison C, Ouyang J, Ghaghda A, Car J. The evolution of mobile apps for asthma: an updated systematic assessment of content and tools. BMC Med. 2015;13:58.

41. Bates DW, Landman A, Levine DM. Health apps and health policy: what is needed?Health apps and health policy health apps and health policy. JAMA. 2018:320(19):1975-6.

\section{Publisher's Note}

Springer Nature remains neutral with regard to jurisdictional claims in published maps and institutional affiliations.

Ready to submit your research? Choose BMC and benefit from:

- fast, convenient online submission

- thorough peer review by experienced researchers in your field

- rapid publication on acceptance

- support for research data, including large and complex data types

- gold Open Access which fosters wider collaboration and increased citations

- maximum visibility for your research: over $100 \mathrm{M}$ website views per year

At $\mathrm{BMC}$, research is always in progress.

Learn more biomedcentral.com/submissions 